\title{
CNSL as Alternate Fuel with Different Additives for CI Engines
}

\author{
Sangeetha Krishamoorthi, M.Prabhahar, Rahul Raj R Pillai, Abdul Manam MK, Abdulla Ajmal
}

\begin{abstract}
The depletion of fossil fuel and the environmental deterioration are the 2 main problems which is faced by the world in recent days. Only limited amount of stocks can provide the fossil fuel based fuels. The various derivatives of the vegetable oils have been identified as the straight vegetative oils which are used in diesel engines. These have the characteristics of high viscosity, lesser volatility level and very low cold flow properties. The CNSL oil was chosen and mixed with several additives and the quality and emission characteristics were described and charted in this paper. Based on the experimental work done the results were compared. The experiments show that the lower blends can be used directly in the engine by which the overall consumption of diesel is reduced. Amongst all the different blends used such as $B 20, B 15$ and B10 the blend B20 was preferred showing improved performance in the engine compared to the different blends available. The experiment was done with the different additives such as DiEthylEther (DEE), Ethanol (EA), and Iso Butane(ISO)
\end{abstract}

Keywords: Isobutane, CI engines, quality, Diethyl ether.

\section{INTRODUCTION}

The various vegetable oils and animal fats along with cooking oil which has been already used are the major derivatives of biodiesel. Triglycerides mainly consists of the animal fats and vegetable oil. Chemically, TAG are esters of fatty acids (FA) with glycerol (1,2,3-propanetriol; glycerol is often also called glycerine). The solvent like methanol, ethanol along with butanol has been used to less the viscosity level of the biodiesel. Banapurmath et al.(2008) tested the Diesel engine with different seed and peelings like Jatropha, with Karanja and also the Polanga methyl ester. The authors reported that when the peak cylinder pressure is high the ignition delay will be short for the biodiesel which is not for the diesel. The process of pyrolysis mainly involves heat with the help of a catalyst which is used converts one molecular substance to the another one. The chemical bonds are made in to small molecules without the presence of air and even oxygen also by heating.

Revised Manuscript Received on December 30, 2019.

* Correspondence Author

Sangeetha Krishamoorthi, Associate Professor Department of Mechanical Engineering, AarupadaiVeedu Institute of Technology, Vinayaka Mission Research Foundation, Deemed to be University, sangeethas@avit.ac.in Dr. M. Prabhahar, Associate Professor,Department of Mechanical Engineering, AarupadaiVeeduInstitute of Technology, Vinayaka Mission Research Foundation, Deemed to be University,mprabhahar@gmail.com Rahul Raj R Pillai, UG Scholars, AarupadaiVeedu Institute of Technology, VinayakaMission'S Research Foundation

Abdul Manam MK, UG Scholars, AarupadaiVeedu Institute of Technology, VinayakaMission'S Research Foundation

Abdulla Ajmal, UG Scholars, AarupadaiVeedu Institute of Technology, VinayakaMission'S Research Foundation

(c) The Authors. Published by Blue Eyes Intelligence Engineering and Sciences Publication (BEIESP). This is an open access article under the CC BY-NC-ND license (http://creativecommons.org/licenses/by-nc-nd/4.0/)
The CNSL biodiesel derived its name from decarboxylated cardanol. Transesterification process is not required for the biodiesel which was obtained from CNSL. The engine deposits, injector plugging are some of the causes due to the carbon deposits and pour point when pure oils are used. Transesterification is the chemical process in which the oil is chemically treated so that the oil can be used directly in the engines.

\section{PROPOSED \& LITERATURE REVIEW}

The present study explains us about how the CI engine can perform when the biodiesel blend extracted from different methyl esters is used. After making the biodiesel ready, the emission and the performance characteristics is compared with the diesel performance. T.Eevera et., al.(2009) [1] showed the various properties of cardanol biodiesel when using at different blends. The Cardanol fuel at different loads was tested by using diesel and different biofuel blends. The distillation was done in 2 stages from which cardanol was produced. K. Purushothaman, et.,al. (2009) [2] checked the properties of Orange oil by using Ethanol as an additive without modifying the diesel engine. The B20 blend has 20 percentage of biodiesel and 80 percentage of diesel fuel. K.Rajan and K.R.Senthil Kumar (2010) [4] indicated the various properties of the CI engine by using a jet piston internally. They said that the incomplete combustion is mainly occurring due to inefficient mixing of biodiesel oil with air. The performance attributes disclosed that the Jatrophas methyl ester BTE when compared with base value is higher when the internal jet piston was used. Relative to the base engine piston when the load increased the value of NOX also increased while using the inner jet piston. Raheman.H., and Phadatare .A.G.,(2004) [3] showed that reducing exhaust emissions along with rising torque, brake power, BTE and reducing BSFC has made Karanja esterified oil blends an appropriate solution for diesel and also can help in reducing air pollution. L.Prabhuet., al (2013) [5] revealed that the overall cylinder pressure and the maximum heat release level increased for the increasing blends value. Also when running on biodiesel blends Co and smoke emissions were found to be considerably smaller, but at full load there was a huge increase in NOX value. Amith Kishore Pandianet., al (2018) [6] presented that the low reactivity at low temperatures eliminates uncontrolled engine ignition and hence ethanol or butanol can be used as improvers of octane. They also explored that the diesel engine which is naturally available can be altered by using biodiesel which is pure in nature.

S.Prakashet., al (2019) [7] explained that the international developmental policies 
improves the resources efficiency and also monitors the pollutant release to air, water and land. Moreover the high cetane number makes a shorter delay in ignition and advances the timing of combustion.

\section{RESULTS \& DISCUSSION}

The Results obtained by using CNSL with different additives are shown below.

\section{Brake Specific Fuel Consumption(BSFC)}

Fig. 1 represents the variation in graph between the blend 20 of CNSL oil with various additives. The SFC increases gradually for the different additives and is reviewed clearly below. By the data obtained from the experiment, it's clear that the specific fuel conception of the diesel and B20 CNSL oil exhibit a sudden increase in performance and emission characteristics and later shows a gradual decrease. The result may due to the brake specific fuel conception decreases with different engine load and engine speed. B20 ISO shows a decrease in value as 0.54 becomes 0.3 then finally reaching 0.23 . B20 EA also exhibits a decrease in value as the 0.62 decrease to reach 0.33 finally reaching 0.31 . B20 DEE also shows a decrease in the value as 0.52 to 0.34 to 0.31 . The B20 diesel decrease from 0.55 to 0.34 to finial value of 0.25 . All the values are 0 at $\mathrm{BP}=0$ then shows a sudden increase at BP

$=1$ then gradually decreases

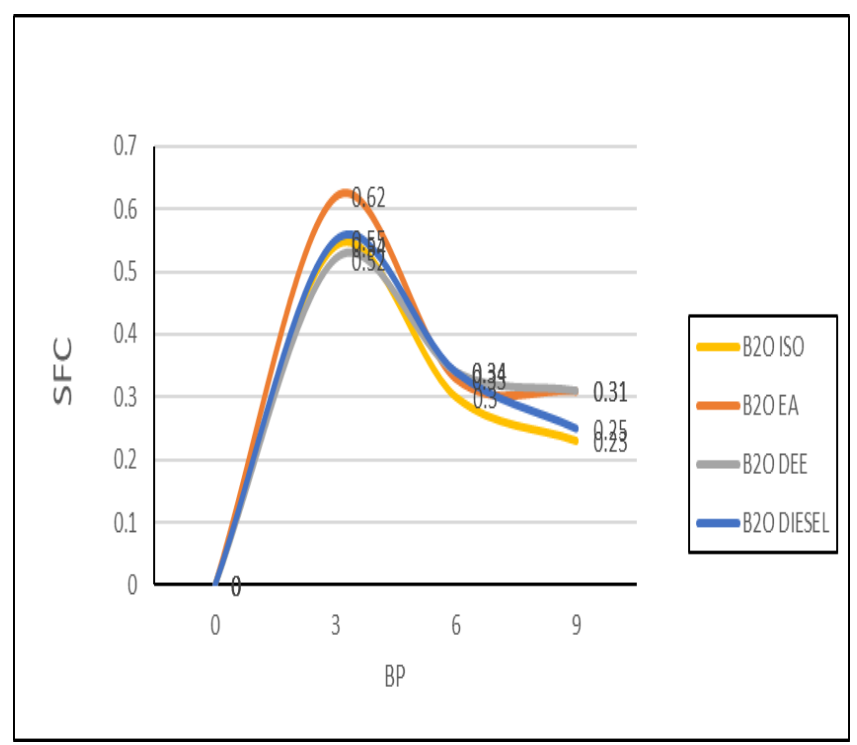

Fig. 1.Brake Specific Fuel Consumption vs Brake Power

\section{Brake Thermal Efficiency}

The slight increase in the BTE when using the different types of additives for the Blend 20 CNSL oil along with diesel is given in the Fig.2. By the data obtained from the experiment in case of BTE it exhibits a slight variation for the B20 ISO variation as compared with other additives. B20 ISO shows a gradual increase by changing from 15.9 to 37.6. B20 EA also exhibits a sudden increase when $\mathrm{BP}=3$ from 13.9 to 27.7 when $\mathrm{BP}=9$. The B20 DEE increase from 16.5 to 25.4 to finally 27.7. In the case of B20 diesel shows a gradual increases as the value ranges from 15.6 to 25.2 to 30.5. All the

values primarily at 0 then increase to values ranging from 27 to 37 for $\mathrm{BP}=3$ to 9 .

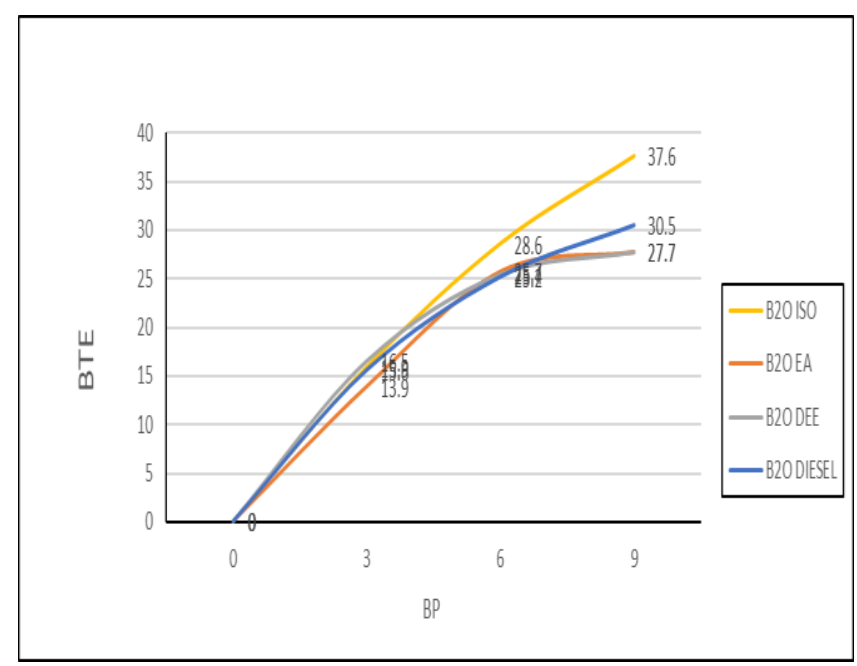

Fig. 2.Brake thermal efficeincy vs Brake power

\section{Carbon Monoxide}

The Fig 3 represents the variation of Carbon Monoxide with different loads of brake power. In this graph the B20 ISO, B20 EA, B20 DEE, B20 Diesel remains same at BP $=0$, ie 0.02 as the $\mathrm{BP}$ increases there is a gradual increases in values. As BP increase B20 ISO increase from 0.02 to 0.023 then to 0.027 at $\mathrm{BP}=9$. Such that B20 DEE also increases values from 0.02 to 0.023 then to 0.027 , finally reaching 0.029 . B20 Diesel also shows increases values from 0.02 to 0.021 then jumping to a value of 0.023 , finally reaching 0.03 .

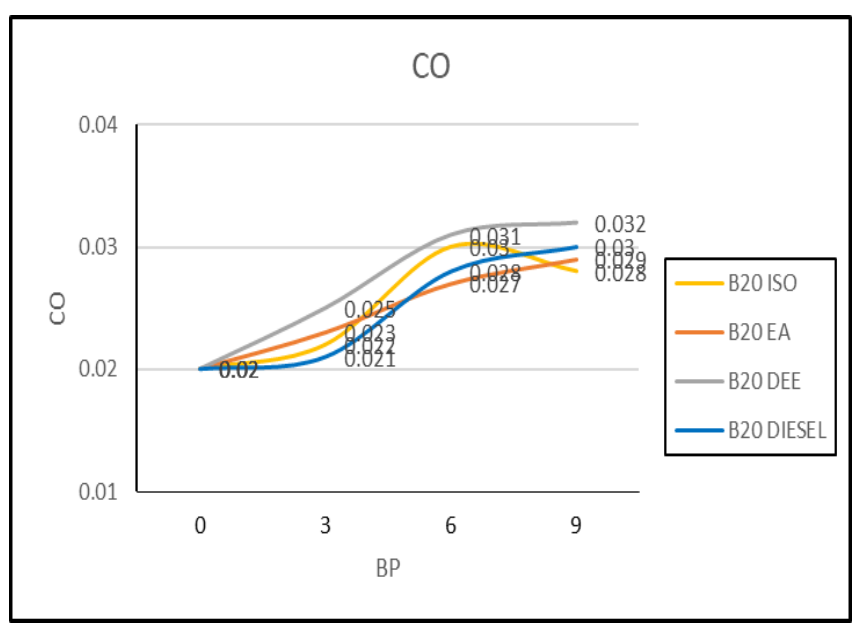

Fig. 3.Carbon Monoxide vs Brake Power 


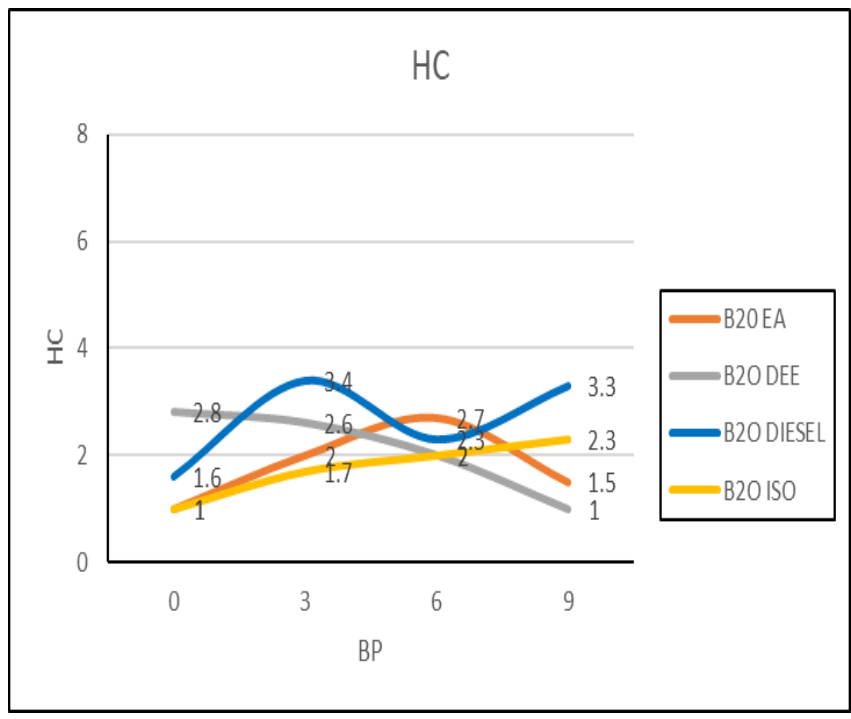

Fig. 4.Hydrocarbon vs Brake Power

The above Fig.4 HC against BP shows various decrease and increase in values. At first as the BP remains zero B20 EA remains 1 , then shows a gradual increase from 2 to 2.7 then decreasing a value of 1.5. B20 DEE also exhibits a gradual decrease in values as the primary value 2.8 at $\mathrm{BP}=0$ becomes 2.6 at $\mathrm{BP}=3$ then to 2 at $\mathrm{BP}=6$ and finally 1 at $\mathrm{BP}=9 . \mathrm{B} 20$ Diesel also exhibits such characteristics ie decrease and increase in values as the values increase from 1.6 to 3.4 when decreases to 2.3 from there to 3.3

\section{Carbon Dioxide}

The Fig.5 indicates the gapin between the Carbon Dioxide and brake power. In this graph against $\mathrm{CO} 2$ vs $\mathrm{BP}$ we can see that except B20 Diesel all other commodities has a different value at $\mathrm{BP}=0$, all the other values remains comparatively similar. B20 ISO shows an increase from 0.6 to 0.9 to 1.3 to finally reaching 1.7. B20 EA exhibit a slow increase from 0.6 to 1 in the initial state and finally reaching 1.5 . The B20 DEE increase from 0.6 to 1.11 then to 1.4 finally reaching 1.5 . And the B20 Diesel increases from 0.5 to 1 then to 1.5 finally reaching 1.6. In this graph it is clear that the B20 ISO blend shows a good emission difference as compared to other alternatives

\section{Nitrogen Oxide}

In the Fig. 6 NOX vs BP, the NOX emission from B20 diesel is showing a sudden jump and a small deviation from others. The B20 ISO , at initial state exhibits a sudden increase as it increases to 90 then to 182 and finally rest in 284. The B20 EA is 39 at initially BP $=0$ increasing to 87 then to 146 then to a sudden jump to 253 . The B20 DEE initially at 54 which is the highest value at $\mathrm{BP}=0$ becomes 166 suddenly then to 183 then to 264. The B20 Diesel is initially 39 at $\mathrm{BP}=0$ like the B20 EA exhibit a sudden jump to 111 then becomes 234 finally reaching 285

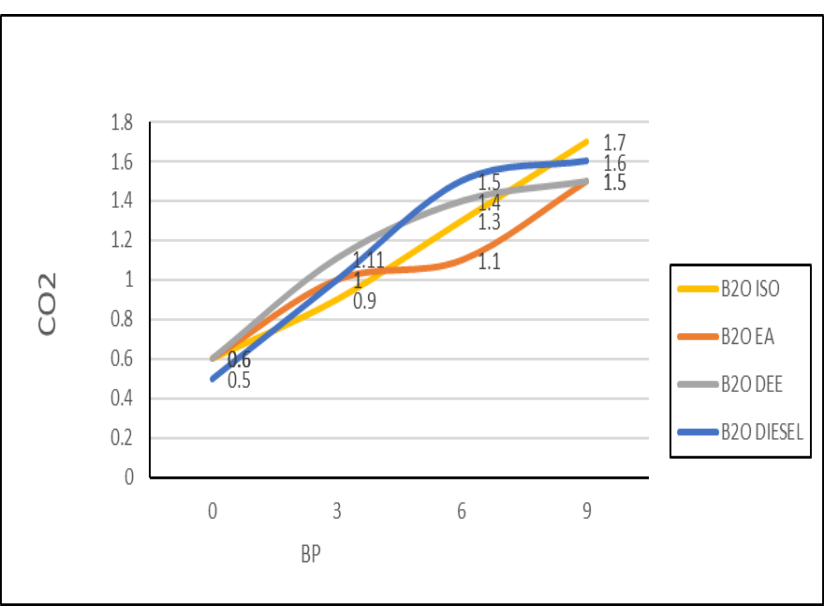

Fig. 5.Carbon dioxide vs Brake Power

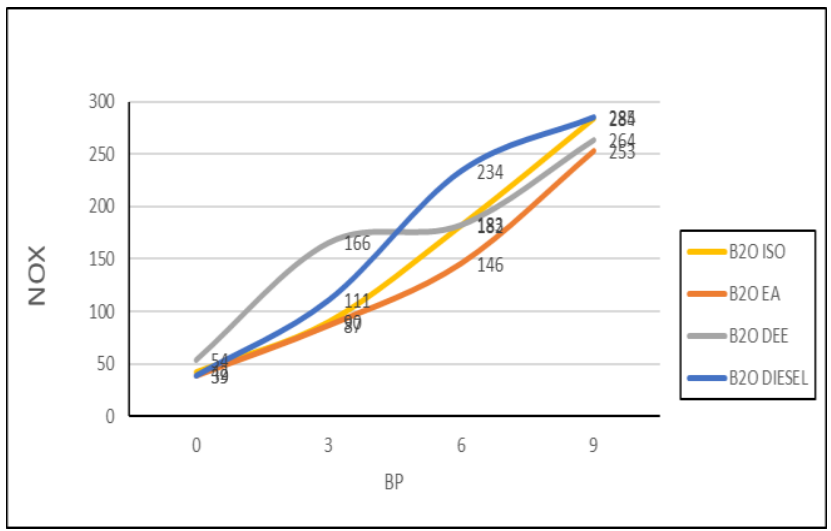

Fig. 6.Nitrogen Oxide vs Brake Power

\section{CONCLUSION}

From each of the test conducted and from the data acquired, it's clear that as far as the data goes the addition of DEE with biodiesel B20 blends produced lower amount of NOx and HC than that of other additives. Apart from its higher cetane number, it is well known that it has as an highly reactive of other fuel like biodiesel. For B20+10\% ethanol as an additive with CNSL oil, the BSFC is $0.11 \%$ more than the diesel fuel and the brake thermal efficiency value of the biodiesel is 9.3\% lesser than the diesel fuel. The emission of CNSL is for nitrogen oxide is $15 \%$ lower than diesel fuel, the hydrocarbon is $6 \%$ higher than the diesel fuel, the carbon monoxide is $0.06 \%$ higher than diesel fuel, the carbon dioxide is $0.1 \%$ higher than diesel fuel and finally the smoke opacity is $49.9 \%$ is higher than the diesel fuel.. Therefore CNSL oil with the ratio of Blend $20+10 \%$ of ethanol additive may be used in diesel engines without doing any change in the operating characteristics of the engine. Hence CNSL-diesel blend can be substituted as fuel for diesel engine.

\section{REFERENCES}

1. T.Eevers, "Biodiesel production process optimization and characterization to assess the suitability of the product for varied environmental conditions" Renewable Energy 34 : et. al (2009) pp. 762-765

2. K. Purushothaman "Performance, emission and combustion characteristics of a compression ignition engine operating on neat orange oil" Renewable Energy 34 :et.,al. (2009) pp. 242-245 
3. Raheman.H., and Phadatare .A.G.,. 'Diesel engine emission and performance from blends of karaja methyl ester and diesel', Biomass and Bioenergy (2004) 27, 393-397

4. Rajan K and Senthil Kumar KR. Performance and emission characteristic of disel engine with internal jet piston using Jatropha oil methyl ester. International journal of Energy Studies. . (2010)Vol.67 (4).pp.557-566

5. Prabhu L., Satish Kumar S., Anderson A. and Rajan K, "Investigation on Performance and Emission Analysis of $\mathrm{TiO} 2$ Nanoparticle as an Additive for Bio-Diesel Blends", Journal of Chemical and Pharmaceutical Sciences, (2015) Vol. 7, pp. 408-412.

6. Amith Kishore Pandian "Emission and performance analysis of a diesel engine burning cashew nut shell oil bio diesel mixed with hexanol"Petroleum Science, Springer ., et., al (2018) Vol 15, Issue 1. Pp. 176-184

7. S. Prakash, M.Prabhahar, S.SenthilVelan, R.Venkadesh, Sanjay Singh, K.Baskar "Experimental studies on the performance and emission characteristics of an automobile engine fueled with fish oil methyl ester to reduce environmental pollution" Energy Procedia , ICEP 2018.10.1016 j.egypro.2019.2.175., Vol 160. pp 412-419

\section{AUTHORS PROFILE}

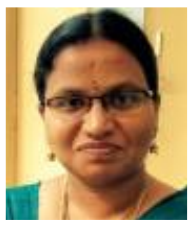

Sangeetha Krishnamoorthi, Associate Professor, Department of Mechanical Engineering AarupadaiVeedu Institute of Technology Vinayaka Mission Research Foundation E-sangeethas@avit.ac.in

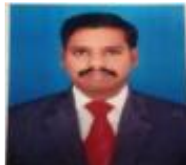

Dr.M.Prabhahar, Assoc. Professor Department of Mechanical Engineering AarupadaiVeedu Institute of Technology Vinayaka Mission Research Foundation E-mprabhahar@gmail.com

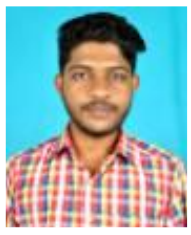

Rahul Raj R Pillai,UG Student, Department of Mechanical Engineering Aarupadai Veedu Institute of Technology Vinayaka Mission Research Foundation

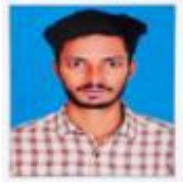

Abdul Manam M K, UG Student Department of Mechanical Engineering AarupadaiVeedu Institute of Technology Vinayaka Mission Research Foundation

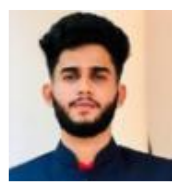

Abdulla Ajamal, UG Student Department of echanical Engineering Aarupadai Veedu Institute of Technology

Vinayaka Mission Research Foundation 